\title{
Use of Methergine for the Prevention of Postoperative Endometritis in Non-Elective Cesarean Section Patients
}

\author{
Murray F. Dweck, Catherine M. Lynch,* and William N. Spellacy \\ Department of Obstetrics and Gynecology, University of South Florida College of Medicine, \\ Tampa, FL
}

\begin{abstract}
Objective: Methergine increases constriction of uterine musculature which may facilitate sloughing of endometrial debris, close uterine vessels, and prevent post-cesarean endometritis. The objective of this study was to evaluate the efficacy of methergine in preventing endometritis in patients undergoing non-elective cesarean section delivery.

Methods: Eighty patients undergoing non-elective cesarean section were enrolled in a prospective randomized clinical trial of methergine (41) versus no methergine (39) administration during the postpartum period. The hospital records were abstracted after discharge to compare the postpartum course.

Results: There were no significant demographic differences between the two groups. The women receiving methergine had a significant reduction in the rate of postoperative endometritis $(10 \% \mathrm{vs}$. $36 \%, P<0.005$ ). In addition, the mean postoperative hemoglobin was significantly higher in the methergine treated group $(P<0.001)$.

Conclusions: The use of methergine postpartum in women undergoing non-elective cesarean sections significantly reduces the incidence of postoperative endometritis and blood loss. Infect. Dis. Obstet. Gynecol. 8:151-154; 2000. @ 2000 Wiley-Liss, Inc.
\end{abstract}

KEY WORDS

endomyometritis; cesarean section; methergine; ergot alkaloid

\begin{abstract}
$A$ major complication of cesarean section is postoperative endometritis. The incidence of this in non-elective cesarean sections is reported to be from $12 \%$ to $95 \%$, depending upon patient population and the indications for surgery. ${ }^{1,2}$ In order to reduce this problem most physicians give prophylactic antibiotics after the umbilical cord is clamped. Despite this precaution, infection remains a significant postoperative morbidity. In the past Eastman recommended postpartum methergine to contract the uterus and to expel necrotic tissue as a means of preventing and treating endometritis, however, little data were available to support the idea. ${ }^{3}$
\end{abstract}

The purpose of this study was to evaluate the effectiveness of postoperative methergine administration in non-elective cesarean section patients in preventing endometritis.

\section{MATERIALS AND METHODS}

This prospective randomized trial was performed in 1997-1998 at Tampa General Hospital. The study was approved by the University Investigational Review Board and all patients signed an informed consent. Inclusion criteria were laboring patients, 18 years of age or older with singleton pregnancies without evidence of intra-amniotic in-

*Correspondence to: Catherine M. Lynch, MD, Department of Obstetrics and Gynecology, University of South Florida College of Medicine, 4 Columbia Drive, Suite 500, Tampa, FL 33606. E-mail: clynch@com1.med.usf.edu 
fection who were undergoing a non-elective cesarean delivery. Women with a previous cesarean section who desired repeat cesarean section were included only if they were in labor at the time of admission. The women had to be able to understand a consent in English, have normal blood pressures, and have no contraindications to ergot alkaloid therapy. All patients were given a single dose of prophylactic antibiotics after the umbilical cord was clamped. Randomization was done by sequentially numbered, sealed opaque envelopes. Patients were enrolled at the time of decision for cesarean section and up to six hours postoperatively.

Patients randomized to receive methergine were given $0.2 \mathrm{mg}$ orally every six hours until hospital discharge with the first dose being given within the first six hours after cesarean section. If the patients were diagnosed with endometritis, experienced side effects from methergine, or became hypertensive, the methergine was discontinued. The control group received no methergine.

Endometritis was defined by two temperatures of greater than $38^{\circ} \mathrm{C}$ more than six hours apart, excluding the first twenty-four hours postoperatively, with uterine tenderness and/or foul smelling lochia and no other obvious source of infection. ${ }^{4}$ Temperatures were taken orally using a digital thermometer.

Charts were reviewed and abstracted after the patients were discharged from the hospital. The data collected included age, parity, race, maternal weight, gestational age, length of ruptured membranes, utilization of internal monitors, presence of meconium, use of amnioinfusion, indication for cesarean section, estimated blood loss, length of surgery, length of hospital stay, length of febrile morbidity, preoperative and postoperative blood pressure, preoperative and postoperative hemoglobin, and breastfeeding at the time of discharge.

Statistical analysis was performed utilizing SPSS-PG package (SPSS Inc., Chicago, IL), using Chi-squared, Student t-test, and logistical regression analysis. Statistical significance was determined by probability value of $<0.05$. Power analysis was performed using $95 \%$ confidence interval, prevalence of endometritis previously determined at this institution to be $39 \%$ for non-elective cesarean sections for a fourfold decrease in incidence.
TABLE I. Population characteristics

\begin{tabular}{lccc}
\hline & $\begin{array}{c}\text { Control } \\
(\mathrm{N}=39)\end{array}$ & $\begin{array}{c}\text { Study } \\
(\mathrm{N}=41)\end{array}$ & $P$ \\
\hline Agemographics & $\mathrm{yr})$ & $25 \pm 1.1$ & $\mathrm{NS}$ \\
Nulliparous (\%) & 21 & 33 & $\mathrm{NS}$ \\
Race (\%) & & & \\
$\quad$ Caucasian & 30 & 32 & NS \\
Black & 40 & 50 & NS \\
Hispanic & 30 & 18 & NS \\
Maternal wt (kg) & $87 \pm 3.1$ & $80 \pm 2.7$ & NS \\
Gest. age (wk) & $38.8 \pm 0.9$ & $38.2 \pm 0.4$ & NS \\
\hline
\end{tabular}

\section{RESULTS}

Eighty patients were enrolled in the study, with thirty-nine randomized to the control group and forty-one to the study group. None of the patients receiving methergine experienced side effects from the drug.

The demographic data on the subjects are given in Table 1and there were no differences between the two groups. The preoperative and postoperative information is given in Table 2. There were statistically significant differences in indication for cesarean birth, use of intrauterine pressure catheter (IUPC), postoperative hemoglobin, and endometritis.

Fourteen patients $(36 \%)$ in the control group and four patients $(10 \%)$ in the methergine group were diagnosed with endometritis $(P<0.005$, odds ratio $5.2,95 \%$ confidence interval $1.5-17.5$ ). Additionally, while the preoperative hemoglobin values between the two groups were similar, the mean postoperative hemoglobin was $10.2 \mathrm{gm} / \mathrm{dl}$ in the control group and $11.2 \mathrm{gm} / \mathrm{dl}$ in the study group $(P$ $<0.001)$ showing that methergine reduced postoperative blood loss.

In the methergine group there were ten patients with an arrest disorder of labor compared to twenty-one in the control group $(P<0.01)$. Intrauterine pressure catheters were used frequently to diagnose and treat this disorder. They were used in twelve patients in the methergine treated group compared to twenty-three in the control group ( $P$ $<0.01)$. Due to the unequal distribution of these variables between the control and study group, and due to their possible association with endometritis, a forward logistic regression analysis was performed to control for these variables. This analysis demonstrated that the effect of the IUPC and arrest dis- 
TABLE 2. Study variables

\begin{tabular}{|c|c|c|c|}
\hline Variable & Control & Study & $P$ \\
\hline Length of ruptured membranes (hr) & $11.7 \pm 2.0$ & $6.5 \pm 2.3$ & NS \\
\hline Use of fetal scalp electrode & 15 & 9 & NS \\
\hline Use of intrauterine catheter & 23 & 12 & $<0.01$ \\
\hline Presence of meconium & 5 & 4 & NS \\
\hline Amnioinfusion & 11 & 6 & NS \\
\hline \multicolumn{4}{|l|}{ Indication for cesarean } \\
\hline Arrest disorder & 21 & 10 & $<0.01$ \\
\hline Breech & 3 & 9 & NS \\
\hline Refused Trial of Labor & 4 & 11 & NS \\
\hline Fetal indication & 11 & 11 & NS \\
\hline Length of surgery $(\mathrm{min})$ & $57 \pm 4.1$ & $51 \pm 2.7$ & NS \\
\hline Length of febrile morbidity (hr) & $12 \pm 3.3$ & $12.7 \pm 1.6$ & NS \\
\hline Length of hospital stay (hr) & $80 \pm 5.7$ & $73 \pm 4.0$ & NS \\
\hline Breastfeeding at discharge & 20 & 24 & NS \\
\hline Estimated blood loss (ml) & $771 \pm 37.1$ & $743 \pm 29$ & NS \\
\hline Preoperative hemoglobin (gm/dl) & $11.8 \pm 0.2$ & $11.9 \pm 0.2$ & NS \\
\hline Postoperative hemoglobin (gm/dl) & $10.3 \pm 1.0$ & $11.2 \pm 0.2$ & $<0.001$ \\
\hline Preoperative blood pressure $(\mathrm{mmHg})$ & $121 / 72 \pm 2 / 1$ & $1 / 8 / 68 \pm 2 / 1$ & NS \\
\hline Postoperative blood pressure $(\mathrm{mmHg})$ & $118 / 66 \pm 1 / 1$ & $115 / 66 \pm 3 / 2$ & NS \\
\hline Postoperative endometritis (\%) & 36 & 10 & $<0.005$ \\
\hline
\end{tabular}

order did not explain the effect of methergine on infection. Forward logistic regression analysis revealed methergine was negatively associated with infection $(\mathrm{R}=-0.24, P<0.01)$.

\section{DISCUSSION}

In older textbooks of obstetrics methergine was recommended postpartum to prevent and treat endometritis, but studies of its efficacy were lacking. ${ }^{3}$

In a review of the world's literature three researchers have looked at the potential benefits of using methergine in the postpartum period. Arabin et al., in a placebo-controlled study, found no significant difference in endometritis between cesarean section patients who received methergine versus placebo. ${ }^{5}$ In addition, Galazios et al., in a retrospective chart review of methergine given per hospital protocol over a two-year period, showed no statistically significant difference between endometritis rates in cesarean section patients who received methergine versus those who did not receive methergine. ${ }^{6}$ Both of these studies, however, included the elective and non-elective cesarean sections as well as vaginal deliveries. In 1989, Iatrakis et al. compared single dose versus multiple doses of methylergometrine in both vaginal birth patients and cesarean section patients. They analyzed the vaginal and cesarean groups separately and found that there was a decrease in the rate of endometritis in those cesarean section patients receiving multiple doses of methergine. ${ }^{7}$

The present prospective randomized study utilized a patient population at high risk for developing postpartum endometritis, namely non-elective cesarean section patients. The results demonstrated that the methergine treated group had a significantly reduced rate of endometritis ( $10 \%$ vs. $36 \%$ ) and a higher postoperative hemoglobin level.

Methergine causes uterine contraction that constricts blood vessels and reduces blood loss. Methergine may then result in a decrease in endometritis by facilitating uterine involution and expulsion of uterine decidua, thereby limiting the nidus for bacterial growth. In this small sample, there were no adverse side effects from methergine as determined by no withdrawal due to side effects.

In conclusion, methergine is safe, inexpensive, and effective in preventing postoperative endometritis and blood loss in non-elective cesarean section patients. Its routine use postoperatively should be seriously considered if no contraindications exist.

\section{REFERENCES}

1. Creasy RK and Resnik R. Maternal Fetal Medicine: Principals and Practice, 3rd Ed. Philadelphia, PA: WB Saunders Company, 1994. pp 649-651.

2. Gibbs RS. Infection after cesarean section. Clin Obstet Gynecol 1985;28:697. 
3. Eastman, EJ. Williams Obstetrics, 11th Ed. New York, NY: Appleton-Century-Crofts, Inc., 1956. p 998.

4. Cox S, Gilstrap LC. Postpartum endometritis. Obstet Gynecol Clin North Am 1989;16:363.

5. Arabin B, Ruttgers H, Kubli F, Auswirkungen der rutinemassign Application von Methylergometrine im Wochenbett, Z Geburtshilfe Frauenheilkd 1986;46: 215-20.
6. Galazios G, Messinis I, Deliyannis D, Tsoumeleka E, Anastasiadis P, Lolis D. Effects of uterine activity stimulants on the incidence of postpartum infections. Arch Hellen Med 1986;3:91.

7. Iatrakis GM, Sakellaropoulos GG, Kourounis G, Argyroudis E. Methylergometrine and puerperal infections after normal delivery and after cesarean section. Isr J Med Sci 1989;25:714-715. 


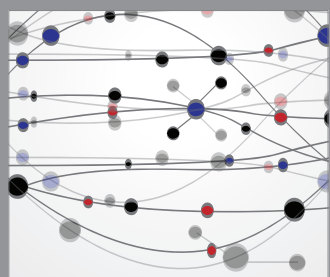

The Scientific World Journal
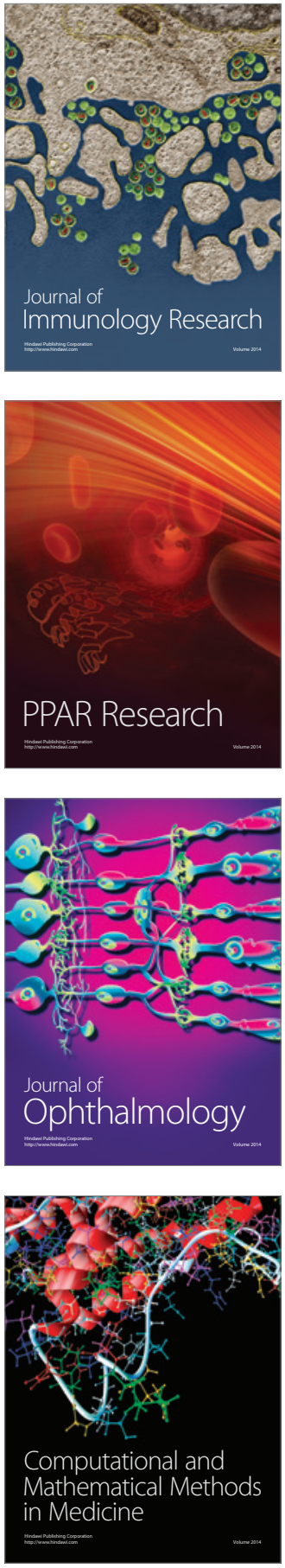

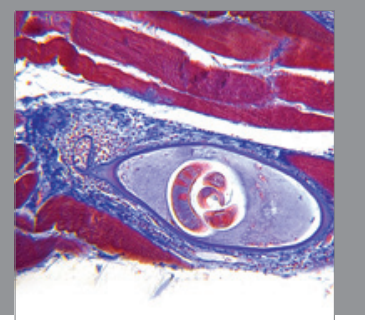

Gastroenterology

Research and Practice
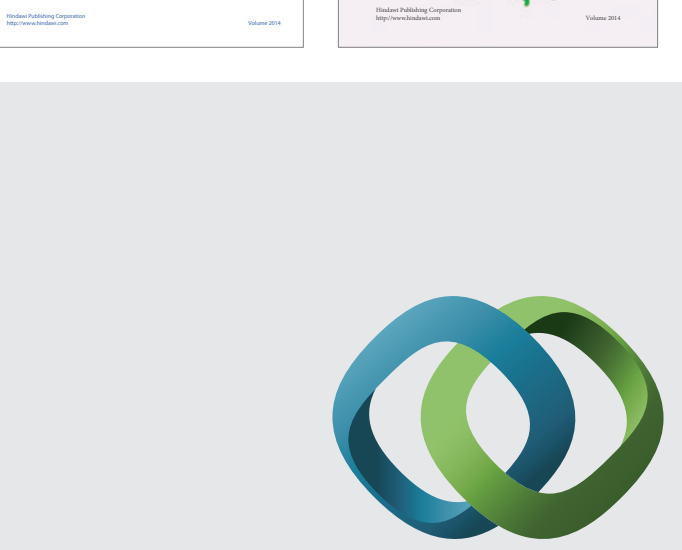

\section{Hindawi}

Submit your manuscripts at

http://www.hindawi.com
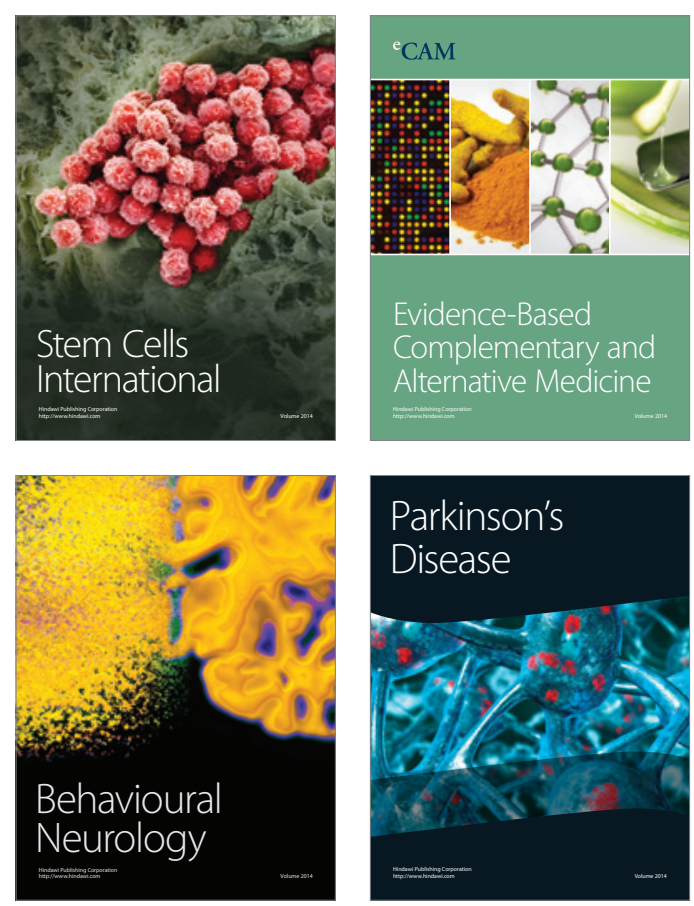

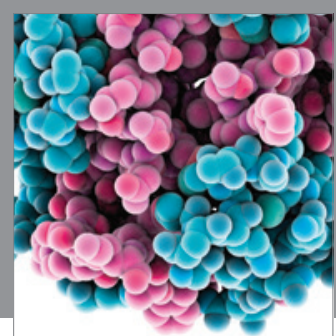

Journal of
Diabetes Research

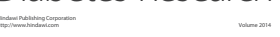

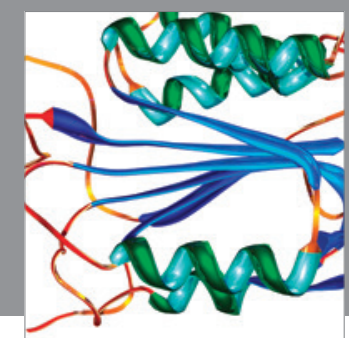

Disease Markers
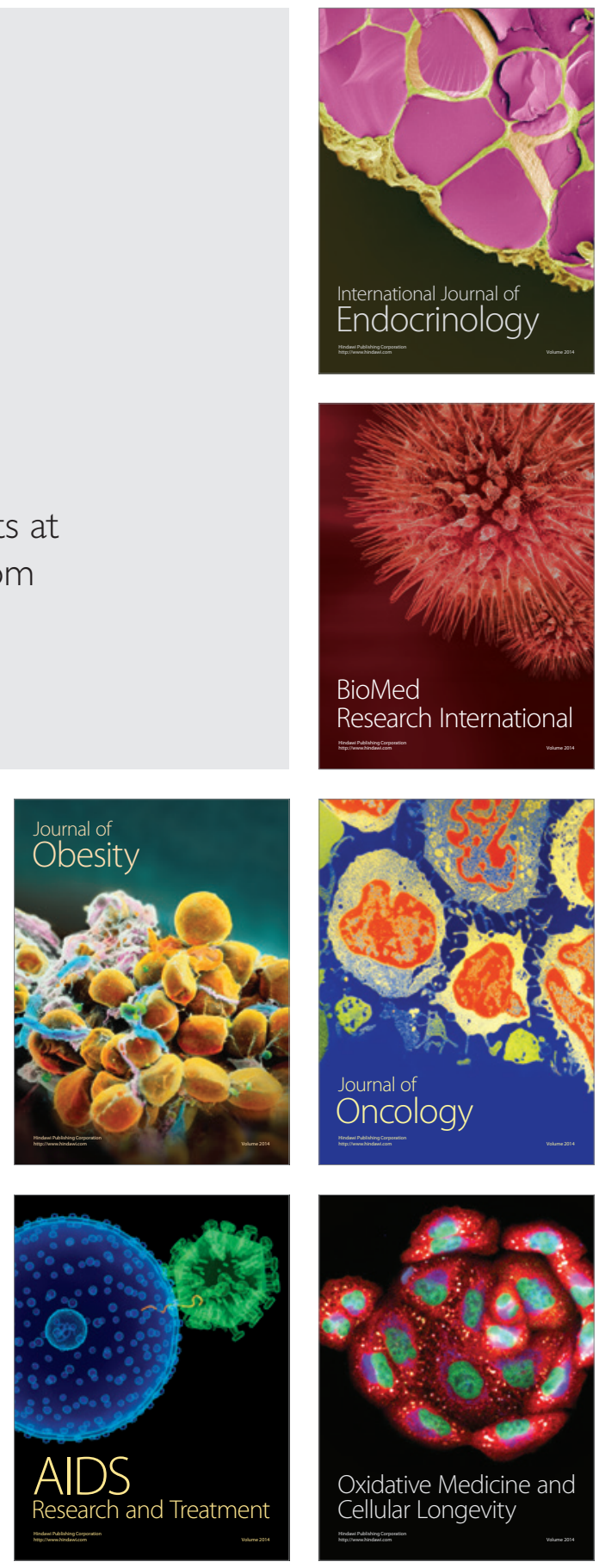